\title{
Mitral valve repair for degenerative mitral regurgitation in patients with left ventricular systolic dysfunction: early and mid-term outcomes
}

Jun Li ${ }^{1,2 \dagger}$, Yun Zhao ${ }^{1,2+}$, Tianyu Zhou ${ }^{4}$, Yongshi Wang ${ }^{2,3}$, Kai Zhu ${ }^{1,2}$, Junyu Zhai ${ }^{1,2}$, Yongxin Sun ${ }^{1,2}$, Hao Lai ${ }^{1,2^{*}}$ and Chunsheng Wang ${ }^{1,2^{*}}$

\begin{abstract}
Background: This study aims to evaluate the early and mid-term outcomes of mitral valve repair for degenerative mitral regurgitation (MR) in patients with left ventricular systolic dysfunction.

Methods: From January 2005 to December 2016, the profiles of patients with degenerative MR who underwent mitral valve repair at our institution were analyzed. Left ventricular systolic dysfunction was defined as an ejection fraction $<60 \%$ or left ventricular end-systolic dimension $>40 \mathrm{~mm}$. Finally, 322 patients with left ventricular systolic dysfunction were included in this study. The prognosis of left ventricular function during follow-up was evaluated and preoperative factors associated with deteriorated left ventricular systolic function during follow-up were analyzed.

Results: The in-hospital mortality rate was $1.6 \%$. The rate of eight-year overall survival, freedom from reoperation for mitral valve and freedom from recurrent MR were 96.9, 91.2 and 73.4\%, respectively. Intraoperative residual mild MR (hazard ratio 4.82) and an isolated anterior leaflet lesion (hazard ratio 2.48) were independent predictive factors for recurrent MR. During follow-up, 212 patients underwent echocardiography examinations at our institution. Among them, 132 patients had improved left ventricular systolic function, and 80 patients had deteriorated left ventricular systolic. Freedom from recurrent MR was found in $75.9 \%$ of the improved left ventricular systolic function group and $56.2 \%$ of the deteriorated left ventricular systolic function group $(P=0.047)$. An age $>50$ years (odds ratio 2.40 ), ejection fraction $\leq 52 \%$ (odds ratio 2.79) and left ventricular end-systolic dimension $\geq 45 \mathrm{~mm}$ (odds ratio 2.31) were independent risk factors for deteriorated left ventricular systolic function during follow-up.

Conclusions: Mitral valve repair could be safely performed for degenerative MR in patients with left ventricular systolic dysfunction. Intraoperative residual mild MR and an isolated anterior leaflet lesion were independent predictive factors for recurrent MR. An age $>50$ years, ejection fraction $\leq 52 \%$ and left ventricular end-systolic dimension $\geq 45 \mathrm{~mm}$ were independent risk factors for deteriorated left ventricular systolic function during follow-up.
\end{abstract}

Keywords: Degenerative mitral regurgitation, Mitral valve repair, Left ventricular systolic dysfunction

\footnotetext{
* Correspondence: lai.hao@zs-hospital.sh.cn; wang.chunsheng@zs-

hospital.sh.cn

${ }^{\dagger} J u n$ Li and Yun Zhao contributed equally to this work.

'Department of Cardiovascular Surgery, Zhongshan Hospital, Fudan

University, 180 Fenglin Road, Shanghai 200032, China

Full list of author information is available at the end of the article
}

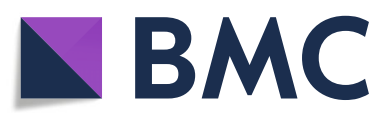

(c) The Author(s). 2020 Open Access This article is licensed under a Creative Commons Attribution 4.0 International License, which permits use, sharing, adaptation, distribution and reproduction in any medium or format, as long as you give appropriate credit to the original author(s) and the source, provide a link to the Creative Commons licence, and indicate if changes were made. The images or other third party material in this article are included in the article's Creative Commons licence, unless indicated otherwise in a credit line to the material. If material is not included in the article's Creative Commons licence and your intended use is not permitted by statutory regulation or exceeds the permitted use, you will need to obtain permission directly from the copyright holder. To view a copy of this licence, visit http://creativecommons.org/licenses/by/4.0/. The Creative Commons Public Domain Dedication waiver (http://creativecommons.org/publicdomain/zero/1.0/) applies to the data made available in this article, unless otherwise stated in a credit line to the data. 


\section{Background}

Degenerative mitral valve (MV) disease is the most common cause of mitral regurgitation (MR) [1]. It is recommended by current guidelines that MV repair should be the primary choice to surgically treat degenerative MR [2-4]. Previous studies have demonstrated that early surgical intervention for degenerative $\mathrm{MR}$ significantly improves early and long-term survival [5, 6]. It has been recommended by the update of the ACC/AHA guidelines that surgery should be performed before left ventricular (LV) systolic dysfunction (class IIa) [4] in experienced centers.

Although early surgical intervention is beneficial for degenerative MR, patients presenting LV systolic dysfunction are not rare in clinical practice. Severe degenerative MR causes LV dilation which leads to more severe MR and increased LV volume overload. Longterm severe MR and LV volume overload is associated with high mortality and morbidity rates [7]; therefore, MV surgery is also necessary in patients with LV systolic dysfunction. However, the safety and effectiveness of MV repair in these patients has not yet been fully evaluated. Studies about the outcomes of patients with LV systolic dysfunction after MV repair are scarce, and the risk factors for mid- and long-term outcomes are unclear. In addition, it is not clear whether LV systolic dysfunction could be improved after MV repair.

This study aimed to analyze the safety and mid-term outcomes of mitral valve repair for degenerative MR in patients with LV systolic dysfunction. We further assessed the potential preoperative factors for deteriorated LV systolic function during follow-up.

\section{Materials and methods}

\section{Patients}

From January 2005 to December 2016, the profiles of all patients with degenerative MR who underwent MV repair at our institution were analyzed. Preoperative characteristics, operative details and perioperative results were acquired retrospectively. An isolated etiology of degenerative disease was confirmed by preoperative transthoracic echocardiography (TTE) and then verified by intraoperative transesophageal echocardiography (TEE) and surgical inspection. LV function was assessed by preoperative TTE. According to current guidelines [4], LV systolic dysfunction was defined as a LV ejection fraction $(\mathrm{EF})<60 \%$ or LV end-systolic dimensions $>40 \mathrm{~mm}$. Except for patient who underwent tricuspid valvuloplasty, left atrial appendage closure and patent foramen ovale closure, patients who underwent other concomitant procedures including aortic valve repair/replacement, coronary artery bypass graft, atrial fibrillation ablation and congenital heart disease surgery etc. were excluded from the study. Finally, 322 patients with LV systolic dysfunction were included. The preoperative details are listed in Table 1.
Table 1 Preoperative profiles

\begin{tabular}{ll}
\hline Age & $52.7 \pm 12.7$ \\
Male & $250(77.6 \%)$ \\
NYHA function classification & \\
Class I & $13(4.0 \%)$ \\
Class II & $109(33.9 \%)$ \\
Class III & $172(53.4 \%)$ \\
Class IV & $28(8.7 \%)$ \\
AF & $81(25.2 \%)$ \\
Hypertension & $137(42.5 \%)$ \\
Diabetes Mellitus & $32(9.9 \%)$ \\
Coronary artery disease & $13(4.0 \%)$ \\
Chronic kidney disease & $3(0.9 \%)$ \\
Chronic obstructive pulmonary disease & $8(2.5 \%)$ \\
Stroke & $7(2.2 \%)$ \\
Preoperative echocardiography & \\
Ejection fraction & $58.7 \pm 7.3$ \\
LV end-systolic dimension & $43.9 \pm 5.9$ \\
LV end-diastolic dimension & $64.9 \pm 7.5$ \\
Left atrial dimension & $54.9 \pm 9.1$ \\
Pulmonary systolic pressure & $52.5 \pm 19.1$ \\
\hline
\end{tabular}

Follow-up information after discharge was obtained through the outpatient department, referring cardiologists and telephone contact. Profiles of overall survival, reoperation for MV and recurrent MR were obtained and analyzed. Recurrent MR was defined as moderate or severe MR detected by TTE during follow-up. The degree of MR was recorded as none or trivial, mild, moderate or severe.

We further analyzed LV systolic function during followup. According to follow-up TTE, we identified patients with improved LV systolic function (increased EF and decreased LV end-systolic dimension) and deteriorated LV systolic function (decreased EF or increased LV endsystolic dimension). To reduce bias, patients who underwent follow-up TTE examinations at other institutions were excluded. We compared differences in preoperative profiles and perioperative details between the improved LV systolic function group and deteriorated LV systolic function group, and then analyzed the potential predictive factors for deteriorated LV systolic function.

This study was reviewed and approved by the institutional review board of Zhongshan Hospital Fudan University and was conducted in accordance with the Declaration of Helsinki. The informed consent was waived.

\section{Operative technique}

In our institution, we intended to perform MV repair in all patients with degenerative $M R$, and intraoperatively, TEE was routinely performed to evaluate MV lesions. 
Proper repair techniques were developed based on a combination of TEE results and surgical inspection. Quadrangular or triangular resection of the prolapse leaflet, artificial chordal reconstruction using expanded polytetrafluoroethylene sutures, and commissural closure were the primary leaflet repair techniques. An artificial annuloplasty band or ring was routinely implanted in $99.1 \%$ of patients.

Routine intraoperative TEE was performed subsequent to separation from cardiopulmonary bypass. Intraoperative reintervention was necessary for moderate or severe residual MR and systolic anterior motion which interfere with hemodynamics. Residual mild regurgitation was generally considered acceptable and did not require reintervention.

Minimally invasive surgery through right thoracotomy was performed in 43 patients. Patients with moderate/ severe tricuspid regurgitation or dilation of the tricuspid annulus $(>40 \mathrm{~mm})$ generally underwent additional tricuspid valvuloplasty. The operative techniques are presented in Table 2.

\section{Statistics}

Continuous variables are expressed as the mean \pm standard deviation, and categorical variables are expressed as counts and percentages. The Kaplan-Meier method was used to compute survival curves. The Cox proportional

Table 2 Operative technique and perioperative outcomes

\begin{tabular}{ll}
\hline Minimal invasive surgery & $43(13.4 \%)$ \\
Tricuspid valvuloplasty & $111(34.5 \%)$ \\
Cardiopulmonary bypass time (min) & $85.6 \pm 27.2$ \\
Aorta cross clamp time (min) & $49.9 \pm 19.5$ \\
Primary repair techniques & \\
$\quad$ Leaflet resection & $179(55.6 \%)$ \\
Chordal reconstruction & $66(20.5 \%)$ \\
Commissural closure & $59(18.3 \%)$ \\
Ring & $24(7.5 \%)$ \\
Size & $30.7 \pm 2.1$ \\
Residual mild MR (TEE) & $35(10.9 \%)$ \\
Postoperative stroke & $5(1.6 \%)$ \\
Renal failure requiring renal replacement therapy & $6(1.9 \%)$ \\
Prolonged ventilation requiring tracheotomy & $8(2.5 \%)$ \\
Poor sternal wound healing & $5(1.6 \%)$ \\
Septicemia & $3(0.9 \%)$ \\
Low cardiac output syndrome & $3(0.9 \%)$ \\
Mediastinitis & $1(0.3 \%)$ \\
Length of stay (days) & $7.5 \pm 3.4$ \\
Intensive care unit (days) & $1.8 \pm 1.3$ \\
Thirty-day mortality & $3(0.9 \%)$ \\
\hline
\end{tabular}

hazards survival model was used to determine univariate and multivariate predictors of all cause death and recurrent MR. Potential predictors of all cause death and recurrent MR were tested in a univariate model and variables with $P<0.1$ were included in the final Cox proportional survival analysis. Hazard ratios with the corresponding 95\% confidence intervals $(\mathrm{CI})$ were calculated.

Preoperative profiles were compared between the improved LV systolic function group and the deteriorated LV systolic function group. One-way analysis of variance and the $\mathrm{x} 2$ test or Fisher's exact test were used to compare continuous and categorical variables, respectively. For abnormally distributed variables, the Kruskal-Wallis test was used to identify differences. Receiver operating characteristic (ROC) curve analysis was used to identify the best cut-off values for preoperative EF, LV endsystolic dimension and end-diastolic dimension for predicting deteriorated LV function during follow-up. Logistic regression analysis was used to determine the univariate and multivariate risk factors for deteriorated LV function during follow-up. The discrimination of the final multivariate risk model was assessed with ROC analysis by computing the area under the curve (AUC). The calibration of the logistic models was assessed with the Hosmer-Lemeshow test. A $P$ value $<0.05$ was considered significant. All statistical analyses were conducted using SPSS software (version 22.0, IBM Corp., Armonk, NY).

\section{Results}

The perioperative outcomes are shown in Table 2. The perioperative complications included stroke (5/322, $1.6 \%)$, acute kidney injury requiring renal replacement therapy $(6 / 322,1.9 \%)$, prolonged ventilation requiring tracheotomy $(8 / 322,2.5 \%)$, low cardiac output syndrome $(3 / 322,0.9 \%)$ and septicemia $(3 / 322,0.9 \%)$. The thirtyday mortality rate was $0.9 \%(3 / 322)$. The cause of death was low cardiac output syndrome in two patients, and multiple organ failure caused by acute kidney injury in one patient.

A total of $89 \%$ of the patients completed follow-up. The average follow-up time was $3.1 \pm 2.6$ years. Eight patients died during follow-up; the cause of death was cardio-related in three patients (heart failure in one and death after reoperation for MV in two), cerebrovascular accident in three patients, pneumonia in one patient and malignant tumor in one patient.

Kaplan-Meier curves for the mid-term outcomes are shown in Fig. 1. The eight-year overall survival, freedom from reoperation for $\mathrm{MV}$ and freedom from recurrent MR were 96.9, 91.2 and 73.4\%, respectively. In the Cox proportional hazard model, a pulmonary artery pressure $>55 \mathrm{mmHg}$ (HR 6.07) and intraoperative residual mild MR (HR 8.00) were independent predictive factors 

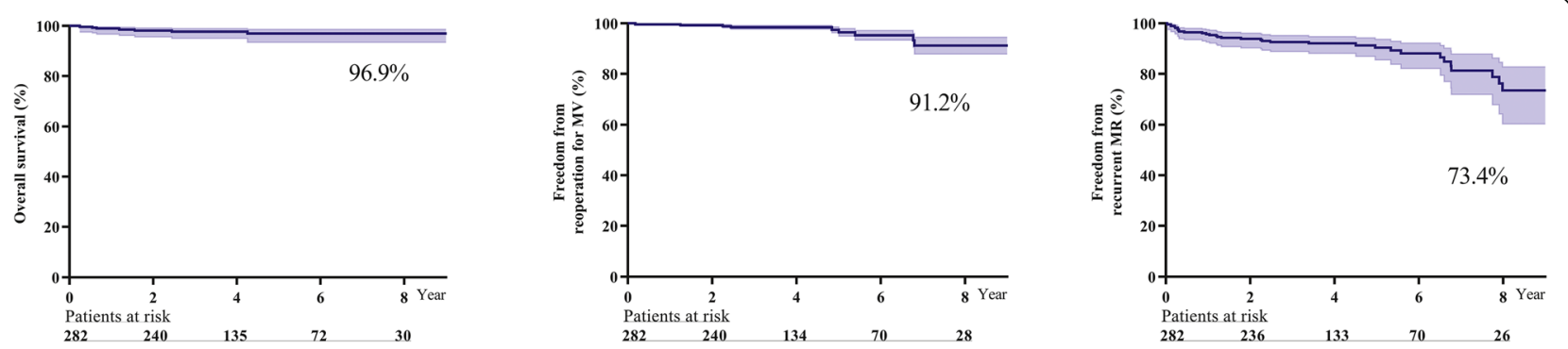

Fig. 1 Kaplan-Meier curves. Eight-year over follow-up, overall survival, freedom from reoperation for mitral valve and freedom from recurrent mitral regurgitation were $95.2,83.7$ and $56.9 \%$, respectively

for all-cause death during follow-up. Intraoperative residual mild MR (HR 4.82) and an isolated anterior leaflet lesion (HR 2.48) were independent predictive factors for recurrent MR during follow-up (shown in Table 3).

During follow-up, 212 patients underwent echocardiography examinations at our institution. Among them, 132 patients had improved LV systolic function, and 80 patients had deteriorated LV systolic function. The preoperative and operative details of these 212 patients are listed in Table 4. Older age, higher NYHA heart function classification, baseline atrial fibrillation, lower EF, and larger LV end-systolic dimension and end-diastolic dimension were associated with deteriorated LV systolic function during follow-up.

In the ROC analysis, the cut-off values of $52.5 \%$ for preoperative EF, $44.5 \mathrm{~mm}$ for preoperative LV endsystolic dimension and $65.5 \mathrm{~mm}$ for preoperative $\mathrm{LV}$ end-diastolic dimension were the most useful for predicting deteriorated LV function during follow-up. The AUCs were 0.578 (95\% CI 0.496-0.659), 0.643 (95\% CI $0.563-0.724)$ and 0.593 (95\% CI $0.512-0.674)$, respectively. In the multivariate logistic regression model, an age $>50$ years (OR 2.40), $\mathrm{EF} \leq 52 \%$ (OR 2.79) and LV end-systolic dimension $\geq 45 \mathrm{~mm}$ (OR 2.31) were identified as independent risk factors for deteriorated LV function during follow-up (shown in Table 5). In the ROC analysis, the AUC was 0.682 (95\% CI $0.605-0.758$ ) for the multivariate logistic regression model. The $P$ value of the model was 0.863 in the Hosmer and Lemeshow test.

Freedom of recurrent MR was found in $75.9 \%$ of the improved LV systolic function group and $56.2 \%$ of the deteriorated LV systolic function group $(P=0.047)$. The Kaplan-Meier curve is shown in Fig. 2.

\section{Discussion}

A previous study demonstrated that heart failure symptoms and a lower EF were associated with higher late mortality [1]. Therefore, in patients with LV systolic dysfunction, including a decreased ejection fraction and increased LV dimension, the effects of MV repair might be compromised. In this study, our results showed that in patients with LV systolic dysfunction, the incidence of perioperative complications was low, and thirty-day mortality was comparable to that in previous studies and our early study [8]. Previous studies have shown that the perioperative mortality rate of MV repair in degenerative MR varies from 0.2 to $1.2 \%[1,6,9,10]$. MV repair was associated with lower mortality than replacement in patients with or without LV dysfunction [11, 12]. These results demonstrated that MV repair could be safely

Table 3 Predictive factors for all cause death and recurrent MR using Cox proportional hazard model

\begin{tabular}{|c|c|c|c|c|}
\hline \multirow[t]{2}{*}{ Variables } & \multicolumn{2}{|l|}{ Univariate model } & \multicolumn{2}{|l|}{ Multivariable model } \\
\hline & Hazard Ratio $(95 \% \mathrm{Cl})$ & $P$ value & Hazard Ratio $(95 \% \mathrm{Cl})$ & $P$ value \\
\hline \multicolumn{5}{|l|}{ All cause death } \\
\hline Age $>60$ years & $4.77(1.14-20.01)$ & 0.03 & / & \\
\hline $\mathrm{PASP}>55 \mathrm{mmHg}$ & $4.79(0.96-23.85)$ & 0.06 & $6.07(1.19-30.9)$ & 0.03 \\
\hline Residual mild MR & $6.45(1.44-28.92)$ & 0.02 & $8.00(1.75-36.63)$ & 0.007 \\
\hline \multicolumn{5}{|l|}{ Recurrent MR } \\
\hline NYHA class III-IV & $2.45(1.06-5.68)$ & 0.04 & / & \\
\hline Isolated anterior leaflet lesion & $2.63(1.30-5.32)$ & 0.007 & $2.48(1.22-5.04)$ & 0.01 \\
\hline Residual mild MR & $5.14(2.40-11.03)$ & $<0.001$ & $4.92(2.26-10.68)$ & $<0.001$ \\
\hline
\end{tabular}

NYHA New York Heart Association, PASP Pulmonary artery systolic pressure, MR Mitral regurgitation 
Table 4 Differences between improved and deteriorated LV function group

\begin{tabular}{|c|c|c|c|}
\hline Variable & Improved LV function $(n=132)$ & Deteriorated LV function $(n=80)$ & $P$ value \\
\hline Age & $50.5 \pm 12.8$ & $54.9 \pm 11.7$ & 0.01 \\
\hline Male & $100(75.8 \%)$ & $66(82.5 \%)$ & 0.25 \\
\hline NYHA function classification & & & 0.009 \\
\hline Class 1 & $9(6.8 \%)$ & $2(2.5 \%)$ & \\
\hline Class II & $53(40.2 \%)$ & $23(28.8 \%)$ & \\
\hline Class III & $63(47.7 \%)$ & $46(57.5 \%)$ & \\
\hline Class IV & $7(5.3 \%)$ & $9(7.5 \%)$ & \\
\hline $\mathrm{AF}$ & $26(19.7 \%)$ & $27(33.8 \%)$ & 0.02 \\
\hline Hypertension & $55(41.7 \%)$ & $41(51.3 \%)$ & 0.17 \\
\hline Diabetes Mellitus & $13(9.8 \%)$ & $9(11.3 \%)$ & 0.75 \\
\hline Coronary artery disease & $8(6.1 \%)$ & $4(5.0 \%)$ & 0.97 \\
\hline Chronic kidney disease & $2(1.5 \%)$ & $1(1.3 \%)$ & 1 \\
\hline COPD & $4(3.0 \%)$ & $3(3.8 \%)$ & 1 \\
\hline Preoperative stroke & $3(2.3 \%)$ & $1(1.3 \%)$ & 0.99 \\
\hline Ejection fraction & $60.0 \pm 5.7$ & $57.4 \pm 7.9$ & 0.01 \\
\hline LV end-systolic dimension & $42.5 \pm 4.6$ & $45.5 \pm 6.5$ & $<0.001$ \\
\hline LV end-diastolic dimension & $63.6 \pm 6.7$ & $66.0 \pm 7.8$ & 0.02 \\
\hline Left atrial dimension & $54.1 \pm 8.5$ & $56.4 \pm 9.6$ & 0.08 \\
\hline Pulmonary systolic pressure & $53.0 \pm 19.6$ & $49.6 \pm 16.6$ & 0.21 \\
\hline Tricuspid valvuloplasty & $42(31.8 \%)$ & $30(37.5 \%)$ & 0.40 \\
\hline Leaflet resection & $80(60.6 \%)$ & $43(53.8 \%)$ & 0.33 \\
\hline Chordal reconstruction & $28(21.2 \%)$ & $13(16.3 \%)$ & 0.38 \\
\hline Commissural closure & $29(22.0 \%)$ & $18(22.5 \%)$ & 0.93 \\
\hline Ring & $8(6.1 \%)$ & $6(7.5 \%)$ & 0.69 \\
\hline Size & $30.8 \pm 2.0$ & $30.8 \pm 2.2$ & 0.77 \\
\hline Cardiopulmonary bypass time (min) & $85.8 \pm 31.1$ & $92.3 \pm 26.8$ & 0.16 \\
\hline Aortic cross clamp time (min) & $50.6 \pm 21.4$ & $52.2 \pm 19.1$ & 0.60 \\
\hline
\end{tabular}

LV Left ventricular, NYHA New York Heart Association, AF Atrial fibrillation, COPD Chronic obstructive pulmonary disease

performed in patients with LV systolic dysfunction, and should be preferred over replacement.

Regarding mid- and long-term outcomes, the 8-year overall survival rate was $96.9 \%$ in this study. Tirone David and colleagues showed in their study that the 10year survival rate for degenerative MR after MV repair was $85.6 \%$ [1]. In in a study conducted by Coutinho et al., the 10-year survival rate for patients with preserved LV function was 89.7\% [9]. In another study, Enriquez-Sarano demonstrated that in patients with heart failure symptoms, an $\mathrm{EF}<60 \%$ and LV end-systolic dimension $>40 \mathrm{~mm}$, the 10 -year survival rate was only

Table 5 Risk factors for deteriorated LV function during follow-up using logistic regression model

\begin{tabular}{|c|c|c|c|c|}
\hline & Odds Ratio $(95 \% \mathrm{Cl})$ & $P$ value & Odds Ratio $(95 \% \mathrm{Cl})$ & $P$ value \\
\hline Variables & Univariate & & Multivariate & \\
\hline Age $\geq 50$ years & $2.72(1.50-4.95)$ & 0.001 & $2.40(1.28-4.52)$ & 0.007 \\
\hline Atrial fibrillation & $2.02(1.08-3.79)$ & 0.03 & / & \\
\hline NYHA class III-IV & $2.08(1.16-3.72)$ & 0.01 & / & \\
\hline$E F \leq 52 \%$ & $2.79(1.06-7.33)$ & 0.04 & $2.79(1.06-7.33)$ & 0.04 \\
\hline LV end-systolic dimension $\geq 45$ mm & $2.95(1.63-5.34)$ & $<0.001$ & $2.31(1.20-4.46)$ & 0.01 \\
\hline LV end-diastolic dimension $\geq 66$ mm & $1.79(1.02-3.16)$ & 0.04 & / & \\
\hline
\end{tabular}

NYHA New York Heart Association, EF Ejection fraction, LV Left ventricular 


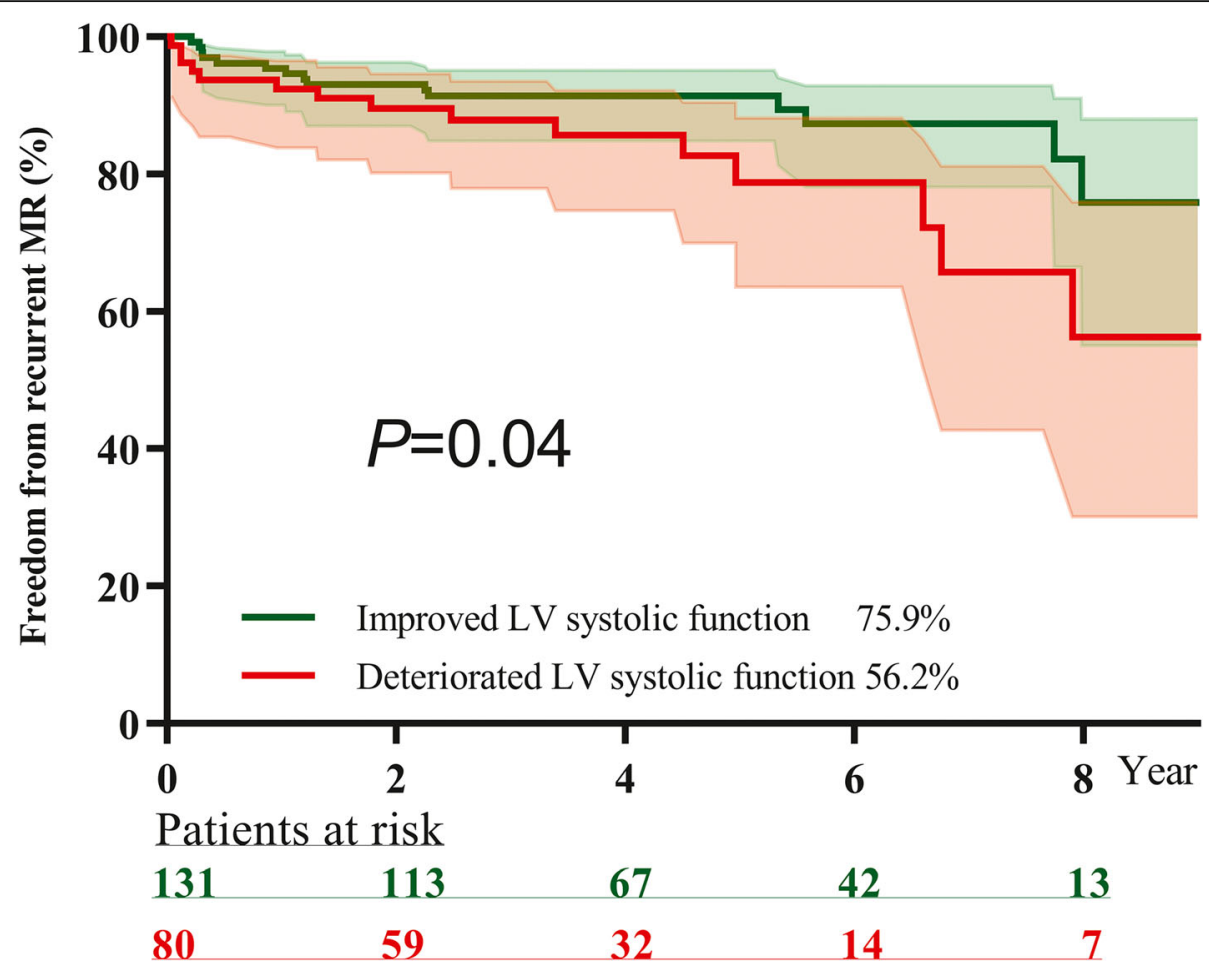

Fig. 2 Comparison of freedom from recurrent MR between improved LV systolic function group (green line) and deteriorated LV systolic function group (red line) during follow-up. At eight years after operation, freedom from recurrent mitral regurgitation was $75.9 \%$ in improved LV systolic function group and $56.2 \%$ in deteriorated LV systolic function group $(P=0.04)$

64\% [10]. Our results suggested that survival after MV repair in isolated degenerative MR patients with LV systolic dysfunction might not be severely compromised. In a previous study, Noack and colleagues evaluated isolated mitral valve repair in patients with reduced left ventricular ejection fraction. They found that the 5-year survival rate were $81.2,75.2$ and $58 \%$ in patients with EFs of $40-49 \%, 30-39 \%$ and $<30 \%$, respectively. Considering that these patients experienced severe HF with a poor prognosis and quality of life, this result was acceptable [13]. Current opinions [6, 14] and guidelines for valve diseases recommend that early surgical intervention is reasonable for severe degenerative MR in asymptomatic patients with preserved LV systolic function, and that these methods could improve outcomes [2-4]. However, patients with LV systolic dysfunction are not uncommon in real world practice. For these patients, "salvage" surgical intervention is still safe, helpful and necessary to prevent further myocardial damage and adverse events.

In this study, the incidence of recurrent MR for patients with LV systolic dysfunction was relatively higher than that in other studies. An early study [15] suggested that the incidence of recurrent MR after MV repair in degenerative disease was high $(28.9 \%$ at 7 years). However, the latest studies $[1,16]$ suggested that the durability of MV repair for degenerative MR was excellent, at approximately $10 \%$ at 10 years. Generally, complex valve lesions (anterior lesion, Barlow disease, etc.) and inappropriate repair techniques were considered to be associated with increased risk of recurrent MR $[9,16$, 17]. We also found in our study that anterior leaflet prolapse and intraoperative residual mild MR were independent predictive factors for recurrent MR; however, in previous studies, patients with preserved LV systolic function constituted most of the patient cohorts. In our previous study [8], we found that recurrent MR was only $3 \%$ at 8-year during follow up for those who received early surgical intervention before the onset of guidelinebased indications. Therefore, preoperative LV systolic dysfunction might be associated with recurrent MR. A dilated left ventricle with LV systolic dysfunction could lead to annular enlargement and apically displaced leaflets, which cause secondary MR. Therefore, persistent LV systolic dysfunction might be a potential cause of recurrent MR. On the other hand, residual mild MR was not only a predictive factor for recurrent MR but was also associated with a higher risk of all-cause mortality. Interestingly, the incidence of recurrent MR was significantly higher in the deteriorated LV systolic function group than in the improved LV systolic function group. Although it was difficult to determine which factor 
initiated the process, progressive MR and LV systolic function could cause a perpetual cycle and lead to poor prognosis. This highlighted the necessity to avoid intraoperative residual MR, especially in patients who already developed LV dysfunction.

Our study found that deteriorated LV systolic function occurred in approximately $38 \%$ of patients. Previous studies have demonstrated that LV systolic dysfunction after MV repair is not uncommon, even in patients with preserved preoperative LV systolic function [18-20]. More importantly, early postoperative LV systolic dysfunction might be persistent and associated with poor long-term outcomes $[18,20]$. In patients with an abnormal EF and enlarged LV dimensions, abnormal myocardial contractile function existed for a significant period. Although abnormal hemodynamics could be corrected by repair operations, LV systolic dysfunction might not be improved due to its prolonged disease stage. Therefore, in patients with preoperative LV systolic dysfunction, it is more important to identify the potential predictors for deteriorated LV systolic function. In this study, an age $>50$ years, $\mathrm{EF} \leq 52 \%$ and LV end-systolic dimension $\geq 45 \mathrm{~mm}$ were identified as independent risk factors by ROC analysis and a logistic regression model for deteriorated LV systolic function during follow-up. Therefore, MV repair should not be delayed in these patients in order to reverse LV systolic dysfunction. Nevertheless, the incidence of recurrent MR and deteriorated LV function during follow-up was relatively high for patients with preoperative LV systolic function, therefore close follow-up was necessary in these patients.

Our study found that more severe heart failure symptoms and preoperative atrial fibrillation were associated with deteriorated LV systolic function, although they were not independent risk factors in multivariate analysis. Several previous studies $[19,21]$ have analyzed the determinants of LV systolic dysfunction after MV repair and also found that preoperative atrial fibrillation and pulmonary hypertension were predictive factors for LV systolic dysfunction as well. Atrial fibrillation and pulmonary hypertension are both signs of the severity of MR and predict a poor prognosis [22]. Therefore, closer follow-up was necessary for patients who presented with a combination of LV systolic dysfunction, severe heart failure function and atrial fibrillation.

In a previous study [23], Imasaka and colleagues suggested that chordal replacement might be associated with better postoperative LV function than leaflet resection in the repair of posterior leaflet prolapse. However, in other studies [19-21], the factors of lesion segment and repair technique were not observed to be related to postoperative LV systolic dysfunction. Our results also suggested that the repair techniques were similar between the improved and deteriorated LV systolic function groups. Nevertheless, due to the potential relationship between recurrent MR and deteriorated LV systolic function, intraoperative residual mild MR should be avoided and managed carefully. In addition, close followup and postoperative echocardiography examinations are necessary for patients with LV systolic dysfunction. In the setting of persistent or deteriorated LV systolic function, the administration of standard anti-heart failure treatment is reasonable.

\section{Limitations}

The present study was observational and retrospective, with the associated biases. Our single center's experience might not apply to other institutions. Additionally, as a large tertiary hospital, we treat patients that come from all areas of the country. Therefore, the follow-up rate was negatively affected by the poor compliance of some patients from remote areas. Hence, approximately 25\% of the follow-up echocardiographic examinations were performed at other institutions. Because we could not confirm every echocardiographic report generated at other institutions, some recurrent cases might have been missed detection. To maintain consistency between preoperative and follow-up echocardiography studies, the analysis of follow-up echocardiography profiles was only conducted for patients who underwent the examinations at our institution. The results might be affected by the sample selection. In addition, the mean follow-up time was relatively short in the present study. Further followup is needed to evaluate repair durability and LV systolic function in these patients.

\section{Conclusion}

For patients witn degenerative MR with LV systolic dysfunction, MV repair could be safely performed with excellent mid-term survival outcomes. Intraoperative residual mild MR and an isolated anterior leaflet lesion were independent predictive factors for recurrent MR. An age $>50$ years, $E F \leq 52 \%$ and LV end-systolic dimension $\geq 45 \mathrm{~mm}$ were independent risk factors for deteriorated LV systolic function during follow-up.

\begin{abstract}
Abbreviations
MV: Mitral valve; MR: Mitral regurgitation; LV: Left ventricular; EF: Ejection fraction; NYHA: New York Heart Association; TTE: Transthoracic echocardiography; TEE: Transesophageal echocardiography; Cl: Confidential interval; ROC: Receiver operating characteristic curve; AUC: Area under curve; HR: Hazard ratio
\end{abstract}

\section{Acknowledgements}

Not applicable.

\section{Disclosure}

The authors declare that they have no competing interests.

\section{Authors' contributions}

(I) Conception and design: Jun Li, Yun Zhao and Chunsheng Wang; (II)

Administrative support: Chunsheng Wang and Hao Lai; (III) Provision of study 
materials or patients: Jun Li, Yun Zhao, Yongxin Sun, Hao Lai and Chunsheng Wang; (IV) Collection and assembly of data: Tianyu Zhou and Junyu Zhai; (V) Data analysis and interpretation: Jun Li, Tianyu Zhou and Kai Zhu; (VI) Manuscript writing: All authors; (VII) Final approval of manuscript: All authors.

\section{Funding}

The work was supported by the Talent Programme Foundation for the Excellent Backbone of Zhongshan Hospital [2019ZSGG07].

\section{Availability of data and materials}

The datasets used and analyzed during the current study are available from the corresponding author on reasonable request.

\section{Ethics approval and consent to participate}

This study was reviewed and approved by the institutional review board of Zhongshan Hospital Fudan University and was conducted in accordance with the Declaration of Helsinki. The informed consent form was waived.

\section{Consent for publication}

Not applicable.

\section{Competing interests}

The authors declare that they have no competing interests.

\section{Author details}

'Department of Cardiovascular Surgery, Zhongshan Hospital, Fudan University, 180 Fenglin Road, Shanghai 200032, China. ${ }^{2}$ Shanghai Institute of Cardiovascular Diseases, Zhongshan Hospital, Fudan University, 180 Fenglin Road, Shanghai 200032, China. 'Shanghai Institute of Medical Imaging, Zhongshan Hospital, Fudan University, Shanghai, China. ${ }^{4}$ Nuffield Department of Population Health, University of Oxford, Oxford, United Kingdom.

Received: 29 June 2020 Accepted: 21 September 2020

Published online: 01 October 2020

\section{References}

1. David TE, Armstrong S, McCrindle BW, Manlhiot C. Late outcomes of mitral valve repair for mitral regurgitation due to degenerative disease. Circulation. 2013;127(14):1485-92.

2. Vahanian A, Alfieri O, Andreotti F, Antunes MJ, Barón-Esquivias G, Baumgartner $\mathrm{H}$, et al. Guidelines on the management of valvular heart disease (version 2012): the joint task force on the management of Valvular heart disease of the European Society of Cardiology (ESC) and the European Association for Cardio-Thoracic Surgery (EACTS). Eur J Cardiothorac Surg. 2012:42(4):S1-44.

3. Nishimura RA, Otto CM, Bonow RO, Carabello BA, Erwin JP III, Guyton RA, et al. 2014 AHA/ACC guideline for the management of patients with valvular heart disease: a report of the American College of Cardiology/ American Heart Association task force on practice guidelines. Circulation. 2014;129:e521-643.

4. Nishimura RA, Otto CM, Bonow RO, Carabello BA, Erwin JP 3rd, Fleisher LA et al. 2017 AHA/ACC focused update of the 2014 AHA/ACC guideline for the Management of Patients with Valvular Heart Disease: a report of the American College of Cardiology/American Heart Association task force on clinical practice guidelines. Circulation. 2017;135(25):e1159-95.

5. Seeburger J, Borger MA, Falk V, Mantovani F, Michelena HI, Pislaru S, et al. Minimal invasive mitral valve repair for mitral regurgitation: results of 1339 consecutive patients. Eur J Cardiothorac Surg. 2008;34(4):760-5.

6. Yazdchi F, Koch CG, Mihaljevic T, Hachamovitch R, Lowry AM, He J, et al. Increasing disadvantage of "watchful waiting" for repairing degenerative mitral valve disease. Ann Thorac Surg. 2015;99(6):1992-2000.

7. Nishimura RA, Vahanian A, Eleid MF, Mack MJ. Mitral valve disease--current management and future challenges. Lancet. 2016;387(10025):1324-34.

8. Zhou T, Li J, Lai H, Zhu K, Sun Y, Ding W, et al. Benefits of early surgery on clinical outcomes after degenerative mitral valve repair. Ann Thorac Surg. 2018;106(4):1063-70

9. Coutinho GF, Garcia AL, Correia PM, Branco C, Antunes MJ. Long-term follow-up of asymptomatic or mildly symptomatic patients with severe degenerative mitral regurgitation and preserved left ventricular function. J Thorac Cardiovasc Surg. 2014;148:2795-801.
10. Enriquez-Sarano M, Suri RM, Clavel MA, Mantovani F, Michelena HI, Pislaru S. Etc. is there an outcome penalty linked to guideline-based indications for valvular surgery? Early and long-term analysis of patients with organic mitral regurgitation. J Thorac Cardiovasc Surg. 2015;150(1):50-8.

11. Kouris N, Ikonomidis I, Kontogianni D, Smith P, Nihoyannopoulos P. Mitral valve repair versus replacement for isolated non-ischemic mitral regurgitation in patients with preoperative left ventricular dysfunction. A long-term follow-up echocardiography study. Eur J Echocardiogr. 2005;6(6): 435-42.

12. Hannan EL, Samadashvili Z, Smith CR, Lahey SJ, Gold JP, Jordan D, et al. Mitral valve repair versus replacement for patients with preserved left ventricular function without heart failure symptoms. J Thorac Cardiovasc Surg. 2019;157(4):1432-1439.e2.

13. Noack T, Marin Cuartas M, Kiefer P, Garbade J, Pfannmueller B, Seeburger J, et al. Isolated mitral valve repair in patients with reduced left ventricular ejection fraction. Ann Thorac Cardiovasc Surg. 2019;25(6):326-35.

14. Suri RM, Vanoverschelde JL, Grigioni F, Schaff HV, Tribouilloy C, Avierinos JF, et al. Association between early surgical intervention vs watchful waiting and outcomes for mitral regurgitation due to flail mitral valve leaflets. JAMA. 2013;310(6):609-16.

15. Flameng $W$, Herijgers $P$, Bogaerts $K$. Recurrence of mitral valve regurgitation after mitral valve repair in degenerative valve disease. Circulation. 2003; 108(17):e124.

16. Suri RM, Clavel MA, Schaff HV, Michelena HI, Huebner M, Nishimura RA, et al. Effect of recurrent mitral regurgitation following degenerative mitral valve repair: long-term analysis of competing outcomes. J Am Coll Cardiol. 2016;67(5):488-98

17. David TE. Durability of mitral valve repair for mitral regurgitation due to degenerative mitral valve disease. Ann Cardiothorac Surg. 2015;4(5):417-21.

18. Tribouilloy C, Rusinaru D, Szymanski C, Mezghani S, Fournier A. Le'vy F, et al. predicting left ventricular dysfunction after valve repair for mitral regurgitation due to leaflet prolapse: additive value of left ventricular endsystolic dimension to ejection fraction. Eur J Echocardiogr. 2011;12:702-10.

19. Varghese R, Itagaki S, Anyanwu AC, Milla F, Adams DH. Predicting early left ventricular dysfunction after mitral valve reconstruction: the effect of atrial fibrillation and pulmonary hypertension. J Thorac Cardiovasc Surg. 2014;148: 422-7.

20. Quintana E, Suri RM, Thalji NM, Daly RC, Dearani JA, Burkhart HM, et al. Left ventricular dysfunction after mitral valve repair-the fallacy of "normal" preoperative myocardial function. J Thorac Cardiovasc Surg. 2014;148:2752-62.

21. Chan V, Ruel M, Elmistekawy E, Mesana TG. Determinants of left ventricular dysfunction after repair of chronic asymptomatic mitral regurgitation. Ann Thorac Surg. 2015;99(1):38-42.

22. Coutinho GF, Garcia AL, Correia PM, Branco C, Antunes MJ. Negative impact of atrial fibrillation and pulmonary hypertension after mitral valve surgery in asymptomatic patients with severe mitral regurgitation: a 20-year follow-up. Eur J Cardiothorac Surg. 2015;48:548-56.

23. Imasaka K, Tayama E, Tomita Y. Left ventricular performance early after repair for posterior mitral leaflet prolapse: Chordal replacement versus leaflet resection. J Thorac Cardiovasc Surg. 2015;150(3):538-45.

\section{Publisher's Note}

Springer Nature remains neutral with regard to jurisdictional claims in published maps and institutional affiliations.

\section{Ready to submit your research? Choose BMC and benefit from:}

- fast, convenient online submission

- thorough peer review by experienced researchers in your field

- rapid publication on acceptance

- support for research data, including large and complex data types

- gold Open Access which fosters wider collaboration and increased citations

- maximum visibility for your research: over $100 \mathrm{M}$ website views per year

At BMC, research is always in progress.

Learn more biomedcentral.com/submissions 